REPORTE DE CASO

\title{
Polioencefalomalacia asociada a exceso de azufre dietético en bovinos de engorde a corral
}

\author{
Castro $\mathrm{DJ}^{1^{*}}$, Margineda $\mathrm{CA}^{1}$, Cantón GJ ${ }^{2}$ \\ ${ }^{1}$ Estación Experimental Agropecuaria (EEA) Marcos Juarez, Instituto Nacional de Tecnología \\ Agropecuaria (INTA), Argentina. \\ ${ }^{2}$ EEA Balcarce, INTA, Argentina.
}

* Correspondencia: Damián J. Castro, INTA EEA Marcos Juarez, Ruta 12 km. 3

(2580) Marcos Juárez, Córdoba, Argentina.

E-mail: castro.damian@inta.gob.ar

Recibido: 15 Julio 2019. Aceptado: 7 Octubre 2019. Disponible en línea: 21 Octubre 2019

Editor: P. Beldomenico

RESUMEN. Polioencefalomacia (PEM) es un término patológico que se refiere a la necrosis cerebro-cortical. En bovinos las causas más frecuentes son déficit de fibra (acidosis ruminal), déficit de tiamina y exceso de azufre (S) dietéticos. El objetivo de este trabajo es describir un brote de PEM en bovinos de engorde a corral consumiendo exceso de $\mathrm{S}$. El establecimiento afectado suministraba una dieta de terminación compuesta por $45 \%$ de burlanda de maíz, pero 25 días antes del problema se incrementó su inclusión al 70\%. Se efectuó una visita al establecimiento en la cual se recolectaron datos clínicos y epidemiológicos, y se realizó la necropsia de un animal muerto para estudios patológicos y bacteriológicos. Adicionalmente se recolectaron muestras de agua de bebida y alimento balanceado. Se recomendó tratar con tiamina a los animales afectados, con respuesta favorable en la mayoría de los casos. En el examen patológico de cerebro se observó edema y hemorragias, con necrosis cortical severa. El cultivo bacteriológico de encéfalo resultó negativo. El agua de bebida contenía $1 \mathrm{~g} / \mathrm{I}$ de sulfatos y el alimento balanceado $0.48 \%$ de $\mathrm{S}$, de modo que el consumo estimado de $S$ total fue de $0.58 \%$. El exceso dietético de $S$ podría haber estado implicado en el desarrollo de este brote de PEM, siendo éste el primer reporte en Argentina.

SUMMARY. Polioencephalomalacia associated with excess dietary sulfur in feedlot cattle. Polioencephalomacia (PEM) refers to cerebrocortical necrosis. In bovine the most frequent causes of PEM are dietary fiber deficit, thiamine deficiency and excess of sulfur (S). The objective of this work is to report an outbreak of PEM in feedlot cattle consuming $\mathrm{S}$ excess. The affected farm provided a finishing diet composed of $45 \%$ corn destillers grains with solubles, but 25 days before of the problem the inclusion of this component was increased in the diet (up to $70 \%$ ). Clinical and epidemiological data were collected and the autopsy of a dead animal was performed for pathological and bacteriological studies. Additionally, drinking water and balanced meal samples were carried out. Affected animals were treated with thiamine, with a favorable response. In the pathological examination of the brain, edema and hemorrhages were observed, with severe cortical necrosis. The bacteriological culture of encephalon was negative. The drinking water contained $1 \mathrm{~g} / \mathrm{I}$ of sulphates and the food $0.48 \%$ of $\mathrm{S}$, so that the total estimated consumption of $\mathrm{S}$ was $0.58 \%$. Dietary $\mathrm{S}$ excess could have favored the occurrence of this PEM outbreak. To the best of our knowledge, this is the first etiological description of $S$ dietary excess associated with PEM in Argentina.

Palabras clave: bovinos, necrosis cerebro-cortical, azufre

Keywords: cattle, cerebro-cortical necrosis, sulfur

\section{Introducción}

Polioencefalomalacia (PEM) es un término patológico que se refiere al reblandecimiento de la sustancia gris del encéfalo (necrosis cerebro-cortical) (Gould, 2000). En bovinos se ha asociado a múltiples causas, tales como: déficit dietético de fibra, deficiencia de tiamina, exceso de azufre (S) dietético, intoxicación con plomo e intoxicación con sal (Amat et al., 2013; Dore y Smith, 2017). Si bien puede haber casos en los que es impo- sible determinar su etiología, la nutrición generalmente desempeña un rol clave en el desarrollo de este trastorno (Dore y Smith, 2017). En los últimos años el exceso dietético de azufre $(S)$ en bovinos de engorde a corral (EC) ha sido un tema de interés en Norteamérica, debido al advenimiento del suministro de granos de destilería (GD), alimentos con elevado aporte de $S$, sumado a que las dietas concentradas favorecen el desarrollo de PEM y de pérdidas subclínicas por el exceso del mencionado macromineral (Klasing et al., 
2005; Drewnosky et al., 2014). En Argentina también se ha difundido la elaboración y suministro de GD, predominantemente bajo la forma de burlanda húmeda de maíz (BM). Aunque es escasa la información nacional respecto del contenido de $S$ en GD, se ha comunicado que sus aportes son elevados y variables (Brunetti et al., 2015). Otras potenciales fuentes de $S$ dietético pueden ser el agua de bebida (principalmente en forma de sulfatos), plantas crucíferas y mezclas minerales (Gould, 2000).

Si bien la presentación de PEM es esporádica, en Norteamérica es uno de los trastornos neurológicos más comunes en bovinos menores a 18 meses, principalmente entre aquellos que se encuentran en EC (Dore y Smith, 2017). Del mismo modo, en Argentina se la menciona como una de las enfermedades con manifestaciones neurológicas más frecuentes en bovinos menores de 24 meses (Späth y Becker, 2012), sin embargo no se ha dilucidado su etiología (Cantón et al., 2015). El objetivo de este trabajo es describir un brote de PEM en bovinos de EC consumiendo exceso de $S$ dietético.

\section{Materiales y métodos}

En mayo del año 2016, los asesores de un establecimiento de EC ubicado en el departamento Belgrano de la provincia de Santa $\mathrm{Fe}$, solicitaron la visita del Servicio de Diagnóstico Veterinario de INTA Marcos Juárez debido a la aparición de bovinos con signos neurológicos, postración y muerte. El establecimiento contaba con 1890 bovinos en EC, pero el problema se evidenció principalmente en dos corrales con 242 novillitos en terminación, con aproximadamente 50 días de encierre y alrededor de 250 a $350 \mathrm{~kg}$ de peso vivo. Estos corrales recibían una dieta constituida, en base a materia seca (MS), por $45 \%$ de BM, $42.5 \%$ de maíz quebrado, $10 \%$ de silaje de moha y $2.5 \%$ de núcleo vitamínico-mineral, pero desde hacía aproximadamente 25 días del inicio del problema, se había incrementado la $\mathrm{BM}$ al $70 \%$ y reducido el maíz a $17.5 \%$. Durante la visita se realizó la anamnesis, la evaluación semiológica poblacional de la totalidad de los corrales, el examen clínico de los animales enfermos, y la necropsia de un animal muerto naturalmente, que cursó el mismo cuadro clínico observado en el resto de los cohabitantes afectados. Durante el examen post mortem se recolectaron muestras de encéfalo para su análisis histopatológico y bacteriológico, y de líquido cefalorraquídeo (LCR) para bacteriología. Adicionalmente, para su análisis químico se recolectaron muestras de agua de bebida, y se extrajeron 4 muestras de una muestra compuesta por 10 (diez) sub-muestras de alimento balanceado obtenido de los comederos.

Para el estudio histopatológico, un hemi-encéfalo fue fijado durante $72 \mathrm{~h}$ en una solución tamponada de formol al $10 \%$, luego se realizaron reducciones de médula oblonga, puente cerebelar, colículos rostrales, tálamo, corteza frontal, corteza temporal, corteza occipital y cerebelo. Seguidamente, las secciones fueron deshidratadas mediante concentraciones crecientes de alcohol, incluidas en parafina, cortadas a 4 $\mu \mathrm{m}$ de espesor, y coloreadas con hematoxilina y eosina (H\&E). Para bacteriología, se realizaron hisopados de corteza cerebral, médula oblonga y LCR, que se sembraron en agar sangre y agar Mc Conkey, y se incubaron en aerobiosis y microaerofilia durante $48 \mathrm{~h}$ a $37^{\circ} \mathrm{C}$.

Los análisis químicos consistieron en la determinación del $\%$ de $S$ total en la materia seca del alimento balanceado, mediante el método Dumas $\left(\mathrm{LECO}^{\circledR}\right)$, y la determinación de sales totales y sulfatos $\left(\mathrm{SO}_{4}\right)$ en el agua de bebida mediante gravimetría y turbidimetría (Fernández y Brambilla, 2017), respectivamente. La estimación del \% de $\mathrm{S}$ total consumido se realizó asumiendo que bovinos en terminación con $273 \mathrm{~kg}$ de peso vivo (similar al peso promedio de las tropas problema) y a $21^{\circ} \mathrm{C}$ de temperatura ambiente, tienen una ingesta diaria individual de 33 litros de agua de bebida (NRC, 2000). Con dichas consideraciones, los cálculos para la estimación del consumo de $\mathrm{S}$ total se realizaron según el procedimiento descripto por Gould (2000).

\section{Resultados}

Los signos clínicos observados en los animales afectados fueron depresión, ausencia de reflejo de amenaza (ceguera), ataxia, bruxismo, decúbito, pedaleo, opistótonos, nistagmos y muerte, con un curso de 48 a $72 \mathrm{~h}$. La morbilidad acumulada durante un período de aproximadamente 20 días, fue del $12.4 \%$ (30/242). Ante una presentación clínica compatible con PEM, la elevada inclusión dietética de BM y que la misma podría resultar en un exceso de $S$, se recomendó la reducción del nivel de inclusión de $\mathrm{BM}$, y el tratamiento con dexametasona ( $8 \mathrm{mg} / \mathrm{kg}$ vía endovenosa) y tiamina ( $20 \mathrm{mg} / \mathrm{kg}$ vía endovenosa lenta seguida por aplicaciones de $15 \mathrm{mg} / \mathrm{kg}$ vía intramuscular cada $4 \mathrm{~h}$ hasta que el animal se levantara) a los animales afectados, de los cuales el $70.8 \%$ (17/24) respondió favorablemente. Como resultado, la mortalidad acumulada fue del $3.7 \%(9 / 242)$ y la letalidad del 30\% (9/30).

Durante la necropsia se observó congestión meníngea difusa (Figura 1, A), herniación cerebelar a través del foramen magno, y aplanamiento de las circunvoluciones cerebrales y cerebelares. A la sección de la corteza cerebral, se observaron áreas de reblandecimiento de color amarillo grisáceo y hemorragias multifocales. No se observaron alteraciones macroscópicas en otros tejidos.

En la histopatología de cerebro se observaron alteraciones en la sustancia gris cortical, siendo más severas 

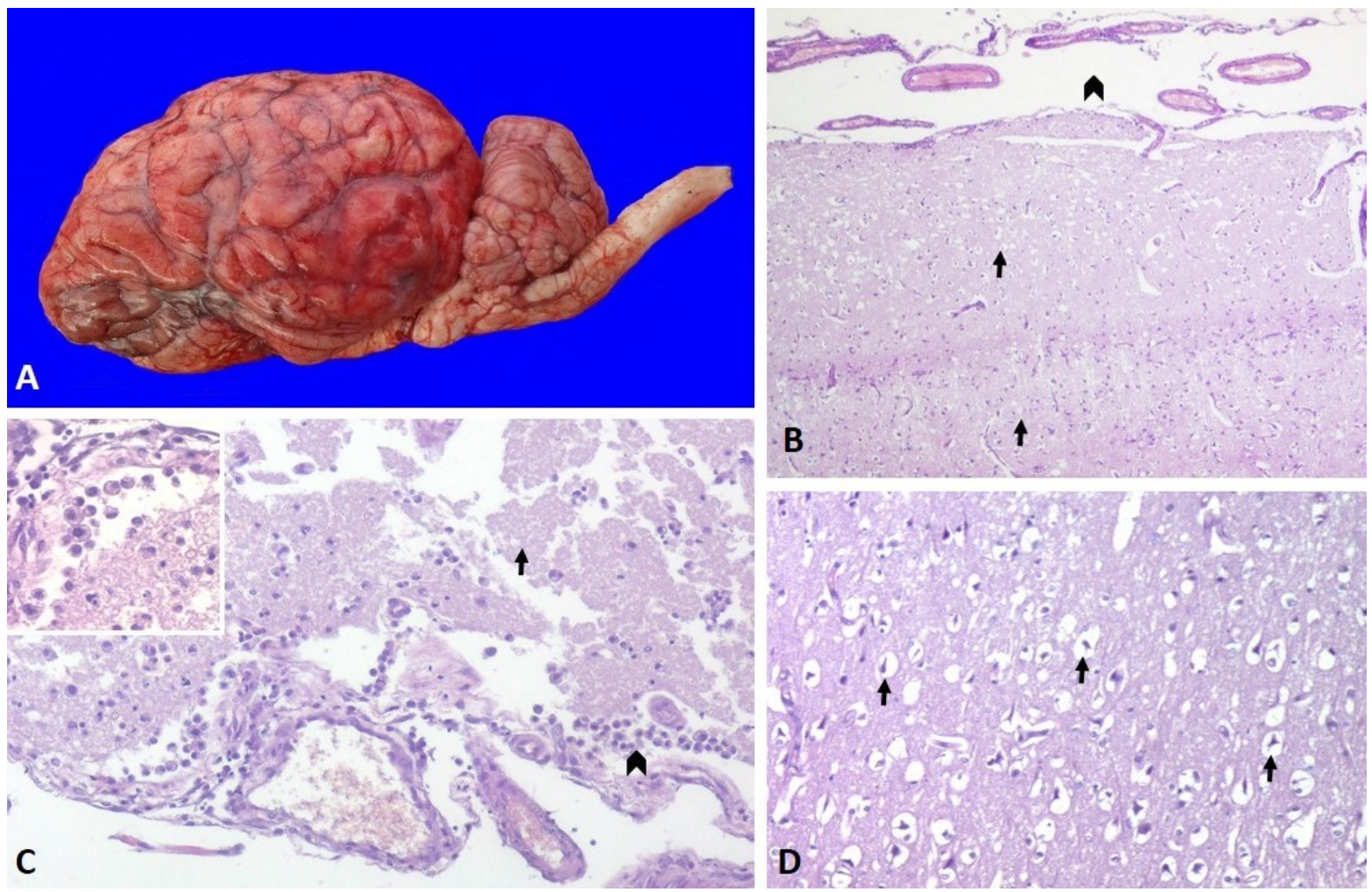

Figura 1. Polioencefalomalacia. A. Congestión meníngea y aplanamiento de las circunvoluciones cerebrales. B. Necrosis laminar cerebrocortical (flechas) y edema sub-meníngeo (cabeza de flecha), H\&E, 50x. C. Corteza cerebral: infiltrado de células Gitter (cabeza de flecha) y zonas de malacia en la capa molecular (flecha), H\&E, 100x. Imagen inserta: células Gitter H\&E, 400x. D. Corteza cerebral: condensación y retracción de somas neuronales (flechas), H\&E, 400x.

en la región occipital. Los hallazgos consistieron en edema severo generalizado perineuronal, peri-vascular y sub-meníngeo, con retracción citoplasmática y picnosis nuclear en neuronas (Figura 1, B y D). En algunos sectores de la capa molecular, se observaron regiones de cavitación rodeadas por material eosinofílico amorfo con infiltrados de macrófagos, muchos de los cuales con marcada expansión y vacuolización citoplasmática (macrófagos espumosos o células Gitter) (Figura 1, C). En pequeñas arteriolas y vénulas se observaron tumefacción de las células endoteliales, infiltrados perivasculares principalmente histiocíticos, y en algunos vasos sanguíneos se observaron hemorragias perivasculares severas. En el resto de las secciones de SNC no se observaron lesiones microscópicas.

El cultivo bacteriológico de las diferentes secciones del SNC y de LCR fue negativo. El agua de bebida contenía $3.1 \mathrm{~g} / \mathrm{l}$ de sales totales y $1 \mathrm{~g} / \mathrm{l}$ de $\mathrm{SO}_{4}$. El alimento balanceado contenía en promedio $0.47 \pm 0.007 \%$ de $S(n=4)$ y el nivel estimado de $S$ dietético total fue de $0.58 \%$.

\section{Discusión}

El diagnóstico de PEM se realizó teniendo en cuenta la signología clínica observada en los animales afectados, los hallazgos patológicos y la respuesta favorable al tratamiento con tiamina. En bovinos jóvenes varias enfermedades pueden ocasionar signología neurológica similar, tales como: coccidiosis nerviosa, listeriosis encefálica, meningoencefalitis trombótica, rabia paresiante, encefalitis por Herpesvirus bovino, entre otras (Späth y Becker, 2012). Estas enfermedades han sido identificadas en Argentina y en nuestro caso fueron descartadas mediante los estudios bacteriológicos y patológicos. Si bien los cuadros de encefalitis por Herpesvirus también presentan necrosis cerebro-cortical, a diferencia de PEM, las lesiones se encuentran principalmente en la región cortical rostral, afectan a la sustancia blanca subcortical como a la base cerebral, el infiltrado inflamatorio es principalmente linfoplasmocítico, el espesor de los infiltrados celulares perivasculares es mayor (Cantile y Youssef, 2016), y clínicamente estos cuadros no responden al tratamiento con tiamina (Cunha, 2010). En este sentido, se ha corroborado que la terapéutica con tiamina es efectiva para la resolución de los casos de PEM, independientemente de su causa, excepto en aquellos animales donde la lesión cerebral sea muy severa al momento de iniciado el tratamiento (Dore y Smith, 2017). La posología recomendada consiste en una primera dosis de 10 a $20 \mathrm{mg} / \mathrm{kg}$ por vía endovenosa lenta, intramuscular o subcutánea, seguida por aplicaciones intramusculares o subcutáneas de la misma dosis cada $8 \mathrm{~h}$ durante un lapso de hasta 3 días en ausencia de respuesta clínica (Apley, 2015). En nuestro caso se aplicó una posología similar, con la que también se obtuvieron buenos resultados. 
La dieta que consumían los animales al momento del brote contenía $0.58 \%$ de $\mathrm{S}$, mientras que para dietas como ésta (con menos de $15 \%$ de forraje), el máximo sugerido es de $0.3 \%$ de $S$ total (Klasing et al., 2005). En este sentido se ha recomendado que para evitar incrementos en la incidencia de PEM en bovinos de EC, consumiendo agua de bebida con el nivel de $\mathrm{SO}_{4}$ observado en el presente estudio $(1 \mathrm{~g} / \mathrm{l})$, la inclusión de GD no debería superar el 23\% (Nichols et al., 2012), mientras que en este caso la dieta contenía $70 \%$. En adición, el intervalo entre el inicio del consumo del exceso de $S$ y el comienzo del brote fue de alrededor de 25 días, coincidente con el período de mayor riesgo de PEM por exceso de S (Drewnosky et al., 2014). Por todo lo anterior, es dable suponer que este brote de PEM fue debido, (o al menos favorecido) a este último factor. Aunque el bajo aporte dietético de fibra efectiva también pudo favorecer la aparición del brote, en el establecimiento no se registraron antecedentes de PEM utilizando el mismo nivel y tipo de forraje, sino hasta después de haber incrementado la inclusión de BM.

Si bien la PEM por exceso de $\mathrm{S}$ dietético, proveniente de GD, agua de bebida y/o forraje, ha sido diagnosticada en Norteamérica (Amat et al., 2013), Reino Unido, Brasil (Sant' Ana y Barros, 2010), Nueva Zelanda y Australia (McKenzie et al., 2009), no existen antecedentes nacionales al respecto, pese al difundido y creciente suministro de GD a bovinos de EC. Pensando que esta etiología haya sido subestimada, es recomendable el monitoreo del contenido de $\mathrm{S}$ total en las dietas de EC, especialmente en aquellas que incluyan GD, considerando también al $\mathrm{S}$ aportado por el agua de bebida.

A pesar de que la morbilidad de PEM generalmente suele ser baja, sus causas más comunes tales como acidosis ruminal, déficit de tiamina y exceso de $\mathrm{S}$ dietético (Dore y Smith, 2017), no solamente pueden ocasionar dicho trastorno, sino también reducciones subclínicas del desempeño productivo (Rammell y Hill, 1986; Karapinar et al., 2010; Drewnosky et al., 2014). En consecuencia, ante el surgimiento de brotes de PEM es recomendable intentar determinar su etiología y evaluar el desempeño productivo de los animales consumiendo la dieta en cuestión, a fin de efectuar las correcciones pertinentes.

\section{Bibliografía}

Amat S, Olkowski AA, Atila M, O'neill TJ. 2013. A review of polioencephalomalacia in ruminants: is the development of malacic lesions associated with excess sulfur intake independent of thiamine deficiency? Vet. Med. Anim. Sci. 1: 110.

Apley, MD. 2015 Consideration of evidence for the therapeutic interventions in bovine polioencephalomalacia. Vet. Clin. Food Anim. 31: 151-161.

Brunetti MA, Frossasco G, Martínez Ferrer J, Gaggiotti MC 2015. Caracterización de co-productos de la industria del etanol. Comunicación. Rev. Arg. de Prod. Anim. 1: 259-322.
Cantile C y Youssef S. 2016. Nervous system. In: Grant Maxie, M. Jubb, Kennedy, and Palmer's Pathology of domestic animals (6th. ed.). Elsevier. USA. Pp. 250-380.

Cantón G, García J, García JA, Moreno F, Morrell E, Odriozola E. 2015. Estudio retrospectivo de reportes de polioncefalomalacia diagnosticados en bovinos en INTA EEA Balcarce. XLIII Jornadas Uruguayas de Buiatría.

Cunha PHJ. 2010. Polioencefalomalacia experimentalmente induzida pela ingestão de dieta com alto teor de enxofre ou pelo herpesvírus bovino 5 em bovinos. Tese de doutorado. Universidade Estadual Paulista Faculdade de Medicina Veterinária e Zootecnia.

Dore V y Smith G. 2017. Cerebral disorders of calves. Vet. Clin. Food Anim. 33: 27-41.

Drewnosky ME, Pogge DJ, Hansen SL. 2014. High-sulfur in beef cattle diets: a review. J. Anim. Sci. 92: 3763-80.

Fernández E y Brambilla E. 2017. Manual del curso teórico práctico: "Entrenamiento en técnicas de diagnóstico e interpretación de resultados". Laboratorio de Bioquímica Clínica Veterinaria. EEA INTA Balcarce.

Gould DH. 2000. Update on sulfur-related polioencephalomalacia. Vet. Clin. North Am. Food Anim. Pract. 16: 481-496.

Karapinar T, Dabak M, Kizil O. 2010. Thiamine status of feedlot cattle fed a high-concentrate diet. Can. Vet. J. 51:1251-1253.

Klasing KC, Goff JP, Greger JL, King JC. 2005. National Academics Press. Pp. 372-385.

McKenzie RA, Carmichael AM, Schibrowski ML, Duigan SA, Gibson JA, Taylor JD. 2009. Sulfur-associated polioencephalomalacia in cattle grazing plants in the family Brassicaceae. Aust. Vet. J. 87:27-32

Nichols CA, Bremer VR, Watson AK, Buckner CD, Harding JL, Smith DR, Erickson GE, Klopfenstein TJ. 2012. Meta-Analysis of the Effect of Dietary Sulfur on Feedlot Health. UNL Beef Report. Paper 680.

NRC. 2000. Nutrient requirements of beef cattle, (7th. ed. rev.) National Academic Press, Washington, D.C. Pp. 81-82.

Rammell CG y Hill JH. 1986. A review of thiamine deficiency and its diagnosis, especially in ruminants. N. Z. Vet. J. 34: 202204.

Sant' Ana FJF y Barros CSL. 2010. Polioencephalomalacia in ruminants in Brazil. Braz. J. Vet. Pathol. 3: 70-79.

Späth EJA y Becker BE. 2012. Análisis epidemiológico de 8 años de diagnóstico de enfermedades de los bovinos (1997-2004). Boletín técnico nำ126. Grupo de Sanidad Animal. EEA INTA Balcarce. 